\title{
Effectiveness of Kinesiotaping in Pregnant Women with Sacroiliac Joint Pain: A Randomized Controlled Study
}

\author{
banu ordahan ${ }^{1}$ and Jule Eriç Horasanlı \\ ${ }^{1}$ Necmettin Erbakan University Meram Faculty of Medicine \\ ${ }^{2}$ Affiliation not available
}

May 1, 2021

\begin{abstract}
Aim Sacroiliac joint dysfunction is an especially common cause of pain during pregnancy. Treatment options during pregnancy are very limited in order to reduce pain and increase the quality of life. We aimed to determine the efficacy of kinesiotaping (KT) in the treatment of sacroiliac joint pain in pregnant women. Methods A total of 50 pregnant women with sacroiliac joint pain were included in the study. Patients were randomized into two groups as KT and sham KT groups. Women in the KT group underwent a total of five weeks of KT once per week; the sham KT group also underwent five weeks of KT applications, but without tension in the kinesiotape. Patients were assessed before and five weeks after the treatment with a visual analogue scale (VAS) for pain and the Roland-Morris Disability Questionnaire (RMDQ) and Pelvic Girdle Questionnaire (PGQ) for disability and quality of life. Results The KT and sham KT groups were similar in terms of age, parity, gravidas, gestational week, and body mass index. At the beginning of the study, there were no statistically significant differences between the two groups in their VAS, RMDQ, or PGQ scores. Five weeks later, the KT group showed significant improvement in all parameters, but no significant differences were observed for the sham KT group in terms of VAS, RMDQ, or PGQ. Conclusions KT treatment improved the pain levels, functioning, and quality of life among pregnant women with sacroiliac joint pain. Keywords Sacroiliac joint pain; Pregnancy; Kinesiotaping
\end{abstract}

\section{Hosted file}

Sacroiliac joint_proofread.pdf available at https://authorea.com/users/411287/articles/ 520376-effectiveness-of-kinesiotaping-in-pregnant-women-with-sacroiliac-joint-pain-arandomized-controlled-study

\section{Hosted file}

table.pdf available at https://authorea.com/users/411287/articles/520376-effectiveness-ofkinesiotaping-in-pregnant-women-with-sacroiliac-joint-pain-a-randomized-controlled-study 

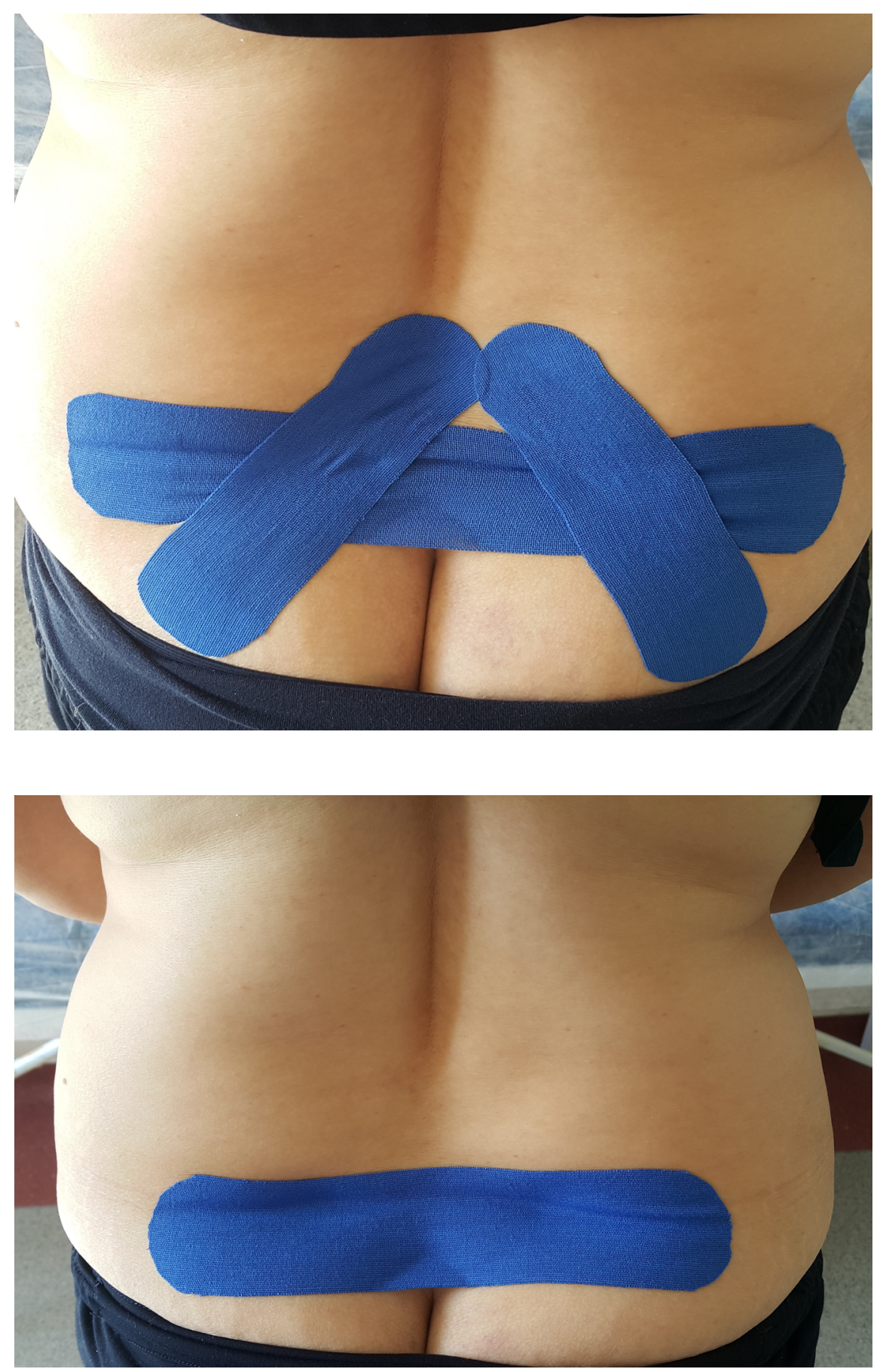

\section{Hosted file}

flow-chart-ali (1).pdf available at https://authorea.com/users/411287/articles/520376effectiveness-of-kinesiotaping-in-pregnant-women-with-sacroiliac-joint-pain-arandomized-controlled-study 